\title{
CROP DIVERSIFICATION AND ITS DETERMINANTS: A COMPARATIVE STUDY BETWEEN CUTTACK AND KANDHAMAL DISTRICTS OF ODISHA, INDIA
}

\author{
Chinmaya Ranjan Kumar \\ Doctoral Fellow (UGC-NET-JRF) in Rural Development, Department of Economics, \\ Ravenshaw University, Cuttack, Odisha, India \\ Email: ckumar.rd@ravenshawuniversity.ac.in
}

\begin{abstract}
The crop diversification is considered as an important pathway for agrarian development. It means not just raising a greater variety of crops in a geographical limit over a period of time but also a movement of resources from a low value agriculture to a high value agriculture. The present study aims at examining the status of crop diversification in Odisha visa-vis the comparison between the coastal district Cuttack and southern tribal Kandhamal district of the state. It is measured through Thiele's Entropy Index (TEI) by considering gross cropped area under eight varieties of crops through secondary data in the year 2015-16 and the two districts have been scrutinized through primary investigation in the year 2018-19. The variables irrigation, fertilizer, high yielding variety seeds, credit, income from agriculture, electricity used for agriculture, telecommunication and farm mechanisation like tractor/ power tiller and statistical tool linear multiple regression have been employed to examine the determinants of crop diversification.
\end{abstract}

Key words: Crop diversification index, Determinants, Regional disparity, Livelihood

\section{Introduction}

Agriculture continues to remain the predominant sector of Indian economy particularly in the backward states like Odisha. Among them 32.1 percent of the family are in Below Poverty Line which seems their livelihood is insecure and they are in challenging and stressed situation. About two-third of the state's works force is still engaged in agriculture which provides them livelihood directly or indirectly even though its share in gross state domestic product (GSDP) has declined from over 70 per cent in the early 1950s to 15.39 per cent in the year 2014-15. The catastrophes, inconsistence of monsoon, climate change risks such as flood, drought which leads to insufficient production of various agricultural products and fluctuation of prices arises owing to inconsistent and become a matter of concern now a day (Birthal and Hazarana, 2019) and it is expected that extreme calamities events rise in future scenario (World Bank, 2013). Under this backdrop, what seems paramount to raise productivity and sustainable agriculture in Odisha's context is to rely heavily on crop diversification. Diversification of agriculture may help to overcome these overriding problems of state's agriculture.

Crop diversification is essential for agriculture based economy in the current scenario. It is defined as movement of production-portfolio from a low-value commodity to high-value commodity making a shift from traditional to commercial crops (Joshi et al., 2004). Diversifying the farm activities helps to mitigate both the climatic risks as well as price risks. Crop rotation and diversification were practiced in farming to control weeds, pest and soil erosion, and to maintain soil fertility. Crop diversification aids in adapting with consumption pattern. Food consumption patterns change noticeably, as consumers in developing countries become richer (Joshi, 2010). People move away from a diet based on staples to one with a greater content of animal products such as meat, eggs and dairy and fruits and vegetables. Diversifying from the monoculture of traditional staple crops can have important nutritional benefits which benefits in food security as well as nutritional security (Lin, 2011). Diversification of agriculture in favour of 
more competitive and high-value enterprises is considered as an important strategy to augment farm income, generate employment, alleviate poverty and conserving the ecological biodiversity and aiding sustainable agricultural transformation (Pingali and Rosegrant 1995, Von Braun, 1995; Joshi et al., 2004; Birthal et al. 2015; King and Hofmockel, 2017; Thapa et al. 2017; Birthal and Hazrana 2019). Diversification in agriculture has tremendous impact on agro socioeconomic and uplifting of resource for poor farming communities. It generates income and employment for rural youth for the ultimate benefits of the farmers in the country (Singh, 2009). Developing country farmers have had considerable success by diversifying crops that can meet export market demand.

Determinants of diversification have several forces to influence the nature and speed of agricultural diversification from staple food to high value commodities. Studies by Joshi et al. (2004) and Rao et al. (2006) have observed that production of high-value commodities is demand-driven, determined mainly by rising income and urbanisation. Hazra (2001) has enlisted other determinants of crop diversification, viz. resource related factors like rainfall, irrigation, fertilizers; technology related factors like High Yielding Variety (HVY) seeds, household related factors like education, income from agriculture; institution related factors like credit, insurance, Minimum Support Prices (MSP), and infrastructure related factors like electricity, telecommunication facilities, road and markets.

The study has attempted

- To measure the level of crop diversification in all districts of Odisha.

- To examine the status and compare the level of diversification between Cuttack and Kandhamal Districts.

- To explore the determinants of crop diversification in the study area.

The limitation of the study is that the present study is made on the available of primary data to examine the determinants of crop diversification where could not covered the variables like agro-climatic zone, soil fertility, rainfall, road connectivity, Minimum Support Price (MSP), marketing facility, education of the farmer and cold storages, food processing units and agrobased industries etc.

\section{Methodology}

In this section an attempt has been made to describe the different as aspects of the methodology adopted in the present study.

\section{Data and Sample Design}

The study has been based on both primary data and secondary data. The secondary data has been collected from various sources like Agricultural Statistics of Odisha and Economic Surveys. The primary data has been collected from two districts of Odisha i.e. Cuttack district and Kandhamal district. In the Cuttack district, the data has been collected mainly from two Gram Panchayats (GP) consists of four villages. One is Govindpur G.P. which consisting of two villages named Biswanathpur, and Jariapda and other is Salagaon G.P. which consisting of Salagaon and Nakhara villages of Tangi- Chaudwar block. In Kandhamal district, has been collected from Balaskumpa and Gudari Gram Panchayat of Khajuripada Block. Primary investigation data has been collected from the households through structured questionnaire. To examined the status of crop diversification of Odisha i.e. district wise, secondary data has been used in the year 2015-16. In the primary study, total sixty numbers respondents were taken from both Cuttack and Kandhamal district each having thirty numbers of farmer's household in the year 2018-19. Both purposive sampling and random sampling technique has been used to select the samples in this study. 
Figure 01: Map of the Study Area

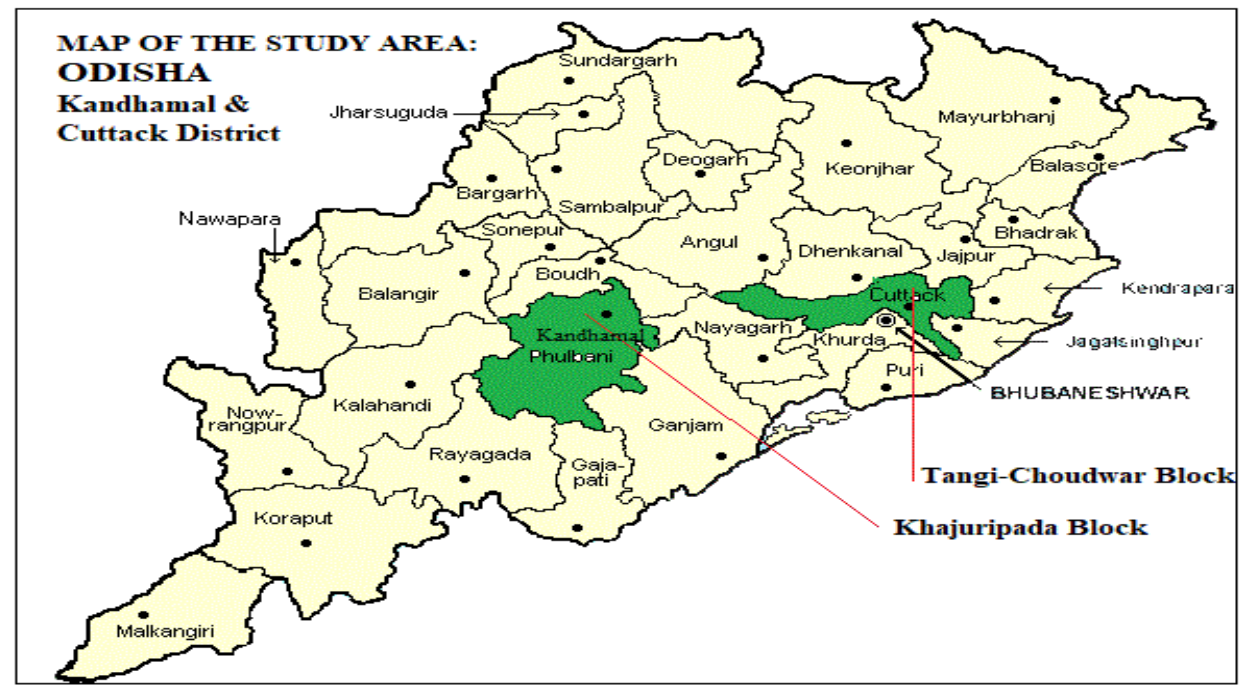

\section{Measurement of Crop Diversification}

Gross Cropped Area (GCA) of eight variety of crops which have been used for measure the Crop Diversification Index (CDI) of Odisha as well as both the Cuttack district and Kandhamal district. These eight varieties of crops are as follows: Cereals, Pulses, Oil seeds, Vegetables, Fruits, Spices, Fibres and Sugarcane. Crop Diversification has been measured on the basis of Theil Entropy Index (TEI), termed as crop diversification index(CDI) where $\mathrm{P}_{\mathrm{i}}=$ the proportion of area under $\mathrm{i}^{\text {th }}$ crop in gross cropped area (GCA), $\mathrm{n}=$ the number of crops i.e. Cereals, Pulses, Oil seeds, Vegetables, Fruits, Spices, Fibres and Sugarcane.

Theil Entropy Index $\left(C D I^{T}\right)=\frac{\sum_{i}^{n} P_{i} \log \frac{1}{P_{i}}}{\log n}$

Range: $0<C D I^{T}<1$

when $C D I=0$, there is complete concentration (no diversification), and where $C D I=1$, there is complete diversification.

\section{Measure the Determinants of Crop Diversification Linear Regression Method}

The impact of the selected explanatory variables on CDI is assessed by linear regressions. The left hand side CDI variable is dependent and right hand side variables like irrigation, electricity, telecommunication, tractor/ power tiller, Credit, fertilizer, HYV, Per capita income from agriculture.

$$
C D I^{T}{ }_{i}=\beta_{0}+\beta_{1} P G I A_{i}+\beta_{2} E L C T_{i}+\beta_{3} T E L C_{i}+\beta_{4} T_{R C T_{i}}+\beta_{5} C R D T_{i}+\beta_{6} F E R T_{i}+\beta_{7} H Y V_{i}+\beta_{8} P C I_{i}+\epsilon_{i}
$$

\section{Variables} Where $\mathrm{i}=1 \ldots \ldots . .30$ no. of households

Variables used to measure determinants of crop diversification are described as follows:

Table 01: Variables used for Determining Crop Diversification

\begin{tabular}{|l|c|l|}
\hline \multicolumn{1}{|c|}{ Variable taken } & Abbreviation & \multicolumn{1}{c|}{ Definition } \\
\hline Irrigation & PGIA & Percentage of gross irrigated area to gross cropped area \\
\hline $\begin{array}{l}\text { Electricity used for } \\
\text { agriculture }\end{array}$ & ELECT & Rural households with electricity connection \\
\hline Telecommunication & TELC & Rural household with Mobile connection \\
\hline Tractor/Power Trailers & TRCT & $\begin{array}{l}\text { Beneficiary having own tractor or power trailers for using } \\
\text { agricultural purpose }\end{array}$ \\
\hline Credit & CRDT & Agricultural credit per hectare of gross cropped area \\
\hline Fertiliser & FERT & NPK (in kg) used per hectare of gross cropped area \\
\hline Seed type & HYV & Percentage of gross cropped area under HYV \\
\hline Per Capita Income & PCl & Per Capita Income from agriculture \\
\hline
\end{tabular}




\section{RESULT AND DISCUSSION \\ Crop diversification in Odisha}

Crop diversification can be measured in a number of ways such as Theil's Entropy Index, Herfindhal Index, Simpson's Index, Ogive Index etc. However, the present study has been employed Theil Entropy Index to measure crop diversification index (CDI). An attempt has been made to understand the relative positions of all the thirty districts of Odisha in relation to crop diversification. There are eight varieties of crops like cereals, pulses, oil seeds; fibre, spices, vegetables, fruits and sugarcane have been included. The position of all the thirty districts of the state in CDI is presented in Table 2. Surprisingly, a backward district like Kandhamal districts remains in the top rank with CDI value 0.70 in the years 2015-16. Baragarh district, which is considered as the rice bowl of Odisha, is in the last rank of the state. The study observes that mostly the tribal dominated KBK districts are in the top ten positions, whereas the relatively richer coastal districts of Odisha except Jajpur are in the bottom. The costal districts like Baleswar, Bhadrak, Jagatsinghpur and Kendapara are in last ten rank of the state. The central Odisha districts are also relatively better in diversification i.e. Angul, Dhenkanal, Keonjhar, Debagarh are in the top ten rank of the state.

Table 02: District-wise Crop Diversification Index of 2015-16

\begin{tabular}{|c|l|r|r|l|r|r|l|r|}
\hline Rank & District & \multicolumn{1}{c|}{ High } & Rank & District & Medium & Rank & District & Low \\
\hline 1 & Kandhamal & 0.70 & 11 & Balangir & 0.45 & 21 & Baudh & 0.39 \\
\hline 2 & Rayagada & 0.61 & 12 & Kalahandi & 0.44 & 22 & Jagatsingpur & 0.39 \\
\hline 3 & Malkangiri & 0.55 & 13 & Sambalpur & 0.44 & 23 & Ganjam & 0.38 \\
\hline 4 & Dhenkanal & 0.54 & 14 & Jharsuguda & 0.43 & 24 & Nabarangpur & 0.37 \\
\hline 5 & Koraput & 0.54 & 15 & Sundargarh & 0.43 & 25 & Baleshwar & 0.37 \\
\hline 6 & Anugul & 0.54 & 16 & Nuapada & 0.42 & 26 & Sonepur & 0.35 \\
\hline 7 & Gajapati & 0.54 & 17 & Nayagarh & 0.42 & 27 & Kendrapara & 0.35 \\
\hline 8 & Keonjhar & 0.48 & 18 & Cuttack & 0.41 & 28 & Mayurbhanj & 0.34 \\
\hline 9 & Debagarh & 0.48 & 19 & Khordha & 0.40 & 29 & Bhadrak & 0.33 \\
\hline 10 & Jajapur & 0.47 & 20 & Puri & 0.39 & 30 & Baragarh & 0.28 \\
\hline
\end{tabular}

Source: Authors' calculation

Figure 02: District-wise Crop Diversification Status of Odisha

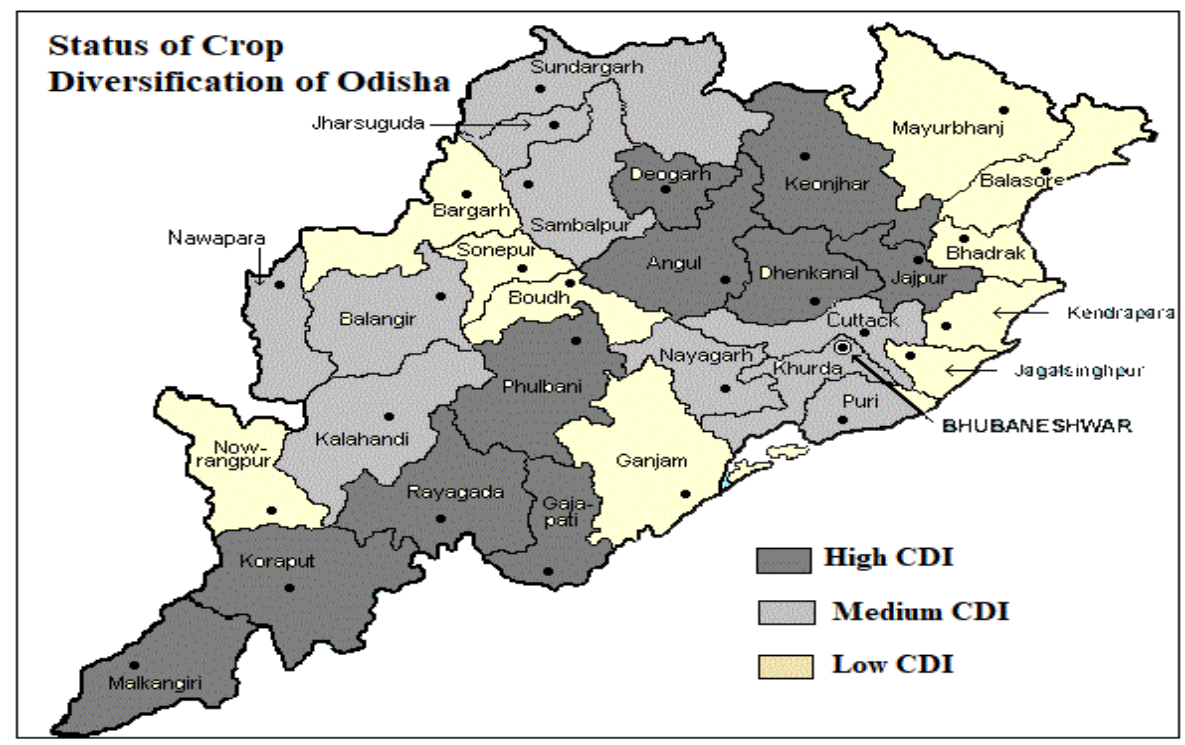

\section{Comparison between Cuttack and Kandhamal district}

The Crop Diversification Index (CDI) for Cuttack and Kandhamal districts have been used same methodology as applied in Odisha. In this section, CDI was measured through Thiel's Entropy Index and the result reveals that Kandhamal district has high CDI, i.e. 0.78 and the Cuttack district has low CDI, i.e. only 0.43 . In the above table, the Crop Diversification Index (CDI) 
shows that the Cuttack district has bottom the status of the CDI result of the Odisha, same situation as in the primary investigation. The result of primary investigation in Cuttack district shows that the CDI is less than the average CDI in comparative to the secondary data investigation. The primary study result shows that average CDI of Cuttack district is 25.4. In comparison to the whole district study in the year 2015-16 shows the CDI of Cuttack is more than the primary data collected from Salagaon and Govindapur G.P.S of Tangi-Chodwar block of Cuttack district. The CDI scenario of Cuttack district might be different in other blocks. As in the secondary data study of Odisha reveals that Kandhamal district is in the top rank of Odisha i.e. CDI is 0.70 . In the primary investigation in Kandhamal district, it is found that the mean of the CDI of Kandhamal district is 0.49 . But in the district level investigation through secondary data shows more $\mathrm{CDI}$ in comparison to the primary investigation.

\section{Determinants of Crop Diversification}

The study has examined several determinants of crop diversification in Kandhamal district. This district has been selected on the basis of the highest crop diversification index in the state as well as in the primary investigation in compared to the Cuttack district. As average CDI of the Kandhamal district shows 0.49 in primary and 0.70 in secondary investigation which is quite high comparison to CDI of Cuttack district which is very less i.e. 0.25 and 0.41 in in primary and secondary investigation respectively. Therefore, it was prudent to take the CDI of Kandhamal district for exploring the determinants of crop diversification. Due to very low CDI in Cuttack district it would be superfluous to examine the exact determinants of crop diversification. Simple statistical tools like linear multiple regressions has been employed to examine the determinants of primary investigation in Kandhamal district. The present study has considered a list of variables which could influence crop diversity. This includes irrigation, electricity, telecommunication, tractor/power trailers, credit, fertiliser, seed type and per capita income from agriculture has been used as independent variables. CDI was taken as the dependent variable in the regression model.

Table 03: Regression results: Determinants of Crop Diversification

\begin{tabular}{|c|c|c|c|}
\hline \multirow[t]{2}{*}{ Variables } & \multicolumn{2}{|c|}{ Unstandardized Coefficient } & \multirow[t]{2}{*}{ P-Values } \\
\hline & Beta & SE & \\
\hline Constant & .166 & .049 & .003 \\
\hline Irrigation & .001 & .001 & .211 \\
\hline Electricity used for agriculture & .000 & .034 & .989 \\
\hline Telecommunication & .033 & .034 & .338 \\
\hline Tractors/ Power trailers & .056 & .025 & .035 \\
\hline Credit & 7.317E-006 & .000 & .003 \\
\hline Fertilizers & .001 & .001 & .285 \\
\hline High Yielding Variety (HYV) seeds & .000 & .000 & .292 \\
\hline Per Capita Income from Agriculture & 4.238E-006 & .000 & .002 \\
\hline R sqaure & \multicolumn{3}{|c|}{.869} \\
\hline Adjusted R sqaure & \multicolumn{3}{|c|}{.819} \\
\hline $\mathrm{F}$ & \multicolumn{3}{|c|}{17.045} \\
\hline P-Value & \multicolumn{3}{|c|}{0.000} \\
\hline
\end{tabular}

Source: Author's Calculation

The analysis has fitted a linear multiple regression models for the primary data collected in the year 2018-19 with CDI as the left hand side variables and the variables explained in table no. 1 . as the right hand side variables. The impact of the selected explanatory variables on CDI is assessed by linear regressions in which the regresses. The left hand side CDI variable is dependent and right hand side variables are independent variables. The results of the study show in the table no. 3, that aggregately all the determinants have significant impact on crop diversification in Kandhamal district of Odisha i.e. the $p$ - value is 0.000 . But variables such as tractor/power trailers, credit, and per capita income from agriculture are individually significant and have positive impact on crop diversification i.e. leads to crop diversification in Kandhamal 
district of Odisha. In contrast, the factors like irrigation, electricity used for agriculture, telecommunication, and fertilizer and HYV seeds have no significant impact on crop diversification in the study area.

\section{Conclusions}

The study finds that crop diversification in Odisha is low. Economically backward district like Kandhamal is ahead in diversification compare to coastal district like Cuttack which gives a paradoxical scenario. It shows that maximum people are engaged in paddy cultivation in Cuttack district rather cultivating numerous crops. But in Kandhamal district, it shows that there has been cultivating different crops such as pulses, vegetables, fruits, oilseeds, spices, plantation crops etc. which leads to crop diversification. The study has examined several determinants of crop diversification in Kandhamal district which shows the highest Crop Diversification Index in the state. In the context of Kandhamal, the factors like credit, tractor/ power trailers and per capita income from agriculture have significant impact on crop diversification. Irrigation, electricity used for agriculture, telecommunication, HYV seeds and fertilizers have no significant impact crop diversification but aggregately all the variables have significant impact on crop diversification. Based on the findings of the study we can suggest that to accelerate the pace of diversification from cereals to high value crops/commercial crops in the state, steps need to be taken to improve credit disbursement for agriculture purpose, farm mechanisation like tractor/ power trailers. Lastly, without consistent policy signals, autonomous efforts by farmers are unlikely to be sufficient to create a sustainable, productive and resilient agriculture sector.

\section{References}

1. Birthal, P. S. \& Hazarana, J. (2019). Crop diversification and resilience of agriculture to climatic shocks: Evidence from India. Agricultural Systems, 173: 345-354.

2. Birthal, P. S., Roy, D. \& Negi, D.S. (2015). Assessing the impact of crop diversification on farm poverty in India. World Development, 72.

3. Hazra, C. R. (2001). Crop Diversification in India, in Papademetriou, M. K. \& Dent, F. J. (Ed), Crop Diversification in the Asia-Pacific Region, Bangkok, Thailand: Food and Agriculture Organization of the United Nations Regional Office for Asia and the Pacific.

4. Joshi, P. K., Gulati A \& Jr. Cummings, R., (2010). Agriculture Diversification in South Asia: Beyond Food Security, in Joshi P.K., Gulati A and Jr. Ralph Cummings (eds.) Agriculture Diversification and Smallholders in South Asia, Academic Foundation, New Delhi.

5. Joshi, P.K., Gulati, A., Birthal, P.S. \& Tewari, L. (2004). Agriculture diversification in South Asia: Patterns, determinants and policy implications. Economic and Political Weekly, 39(18): 24572467.

6. King, A. E. \& Hofmockel, K. S. (2017). Diversified cropping systems support greater microbial cycling and retention of carbon and nitrogen. Agriculture, Ecosystems \& Environment, 240(1): 66-76. Chicago, USA.

7. Lin, B. B. (2011). Resilience in agriculture through crop diversification: adaptive management for environmental change. Bioscience, 61(3):183-93.

8. Pingali, P. L. \& Rosegrant, M. W. (1995). Agricultural Commercialization and Diversification: Process and Policies. Food Policy, 20(3), 171-186.

9. Rao, P., Birthal., P. S. \& Joshi, P. K. (2006). Diversification toward s High Value Agriculture, Role of Urbanisation and Infrastructure. Economic and Political Weekly, 41(26): 2747-2753.

10. Singh, A., Boukerrou, L. \& Miller, M. (2009). Diversification in Agriculture, in: Encyclopaedia of Earth, (Eds.) Cutler J. Cleveland, Washington D.C.

11. Thapa, G., Kumar, A., Roy D. \& Joshi, P.K. (2017). Impact of crop diversification on rural poverty in Nepal. Canadian Journal of Agricultural Economics, 1-35.

12. Von Braun, J. (1995). Agricultural commercialization: Impacts on income and nutrition and implications for policy. Food Policy, 20 (3): 187-202.

13. World Bank, (2013). Turn Down the Heat: Climate Extremes, Regional Impacts, and the Case for Resilience: A Report of the World Bank. World Bank, Washington D.C., U.S. 